Check for updates

Cite this: RSC Adv., 2018, 8, 39314

\title{
Boron carbide composites with highly aligned graphene nanoplatelets: light-weight and efficient electromagnetic interference shielding materials at high temperatures
}

\begin{abstract}
Y. Q. Tan, H. Luo, X. S. Zhou, S. M. Peng* and H. B. Zhang (DD*
$\mathrm{B}_{4} \mathrm{C}$-based ceramic composites containing 0-2 vol\% highly aligned graphene nanoplatelets (GNPs) are fabricated. The electromagnetic interference (EMI) shielding properties of the obtained composites are investigated at $\mathrm{X}$-band $(8.2-12.4 \mathrm{GHz})$ frequency range from room-temperature up to $800{ }^{\circ} \mathrm{C}$. All composites exhibit outstanding EMI shielding properties with satisfactory frequency- and thermalstability. The shielding effectiveness (SE) of $\mathrm{GNP} / \mathrm{B}_{4} \mathrm{C}$ composites increases monotonically with increasing GNP loading. Superior room-temperature SE close to $40 \mathrm{~dB}$ is achieved with only 2 vol\% GNPs and high SE around $35 \mathrm{~dB}$ still persists at $800^{\circ} \mathrm{C}$. Considering their relatively low density, GNP/B ${ }_{4} \mathrm{C}$ composites possess a high specific shielding effectiveness (SSE) of $16 \mathrm{~dB} \mathrm{~cm}^{3} \mathrm{~g}^{-1}$ which is among the highest values in reported ceramic-based shielding composites. Especially, the GNP/B ${ }_{4} \mathrm{C}$ composite with 2 vol\% GNPs exhibits the highest SSE/t (SSE divided by thickness) values at temperatures above $200{ }^{\circ} \mathrm{C}$ for all reported shielding composites, indicating that GNP/B ${ }_{4} \mathrm{C}$ composites belong to the most promising high-temperature shielding composites. The excellent shielding properties of GNP/B ${ }_{4} \mathrm{C}$ composites arise mainly from the high electrical conductivity, high dielectric loss and the multiple reflections by the highly aligned and large-sized GNP layers.
\end{abstract}

Received 3rd September 2018 Accepted 20th November 2018 DOI: $10.1039 / c 8 r a 07351 a$

rsc.li/rsc-advances carbon fiber $\left(\mathrm{C}_{\mathrm{f}}\right)^{14,15}$ carbon nanotube $(\mathrm{CNT})^{16,17}$ and graphene..$^{1-3}$ Specially, it is worth noting that composites containing two-dimensional graphene could achieve considerably high EMI SE at a much lower filler content compared to onedimensional or three-dimensional nano-fillers, ${ }^{18,19}$ and the high SE dominantly arose from the high absorption loss. ${ }^{19}$ Yuan et al. demonstrated that graphene nanoplatelets (GNPs) are more effective in enhancing the electrical conductivity and EMI SE of polymer composites by comparing the EMI shielding properties between single-wall carbon nanotube and graphene sheet/polyaniline composites. ${ }^{19}$ It can be speculated that the two-dimensional nature and high aspect ratio of GNPs played a significant role in enhancing the shielding of EMI and the total SE could be possibly further improved by optimizing the interfaces and microstructure of ceramic composites. ${ }^{11,20}$ Selfaligned reduced graphene oxide ( $\mathrm{rGO}$ ) in epoxy composites could give rises to a remarkable EMI SE of $38 \mathrm{~dB}^{20}$ It was recently reported that the two-dimensional nano-layered MAX phase (a class of layered ternary transition-metal carbides and nitrides with a general formula of $\mathrm{M}_{n+1} \mathrm{AX}$, wherein $\mathrm{M}$ is an early transition metal, $\mathrm{A}$ is an A-group element, $\mathrm{X}$ is either $\mathrm{C}$ or $\mathrm{N}$, and $n$ varies from 1 to 3$)^{21} \mathrm{Ti}_{3} \mathrm{AlC}_{2}$ with higher aspect ratio grains and higher texture degree is more favourable for high EMI SE. ${ }^{22}$ Specially, a giant X-band (8.2-12.4 GHz) EMI SE around $92 \mathrm{~dB}$ was reported in well aligned MXene film which is
Innovation Research Team for Advanced Ceramics, Institute of Nuclear Physics and Chemistry, China Academy of Engineering Physics, Mianyang, 621900, China. E-mail:pengshuming@caep.cn; hbzhang@caep.cn 
another type of highly conductive two-dimensional materials exfoliated from MAX phases. ${ }^{23}$

In addition to the total SE, the specific SE (SSE) defined as the ratio between the total SE and the density of composite is considered as another important criterion to evaluate the EMI shielding materials especially for aerospace applications. ${ }^{23,24}$ In an effort to reduce the weights of the shielding materials, foamstructured composites were produced with the aid of expanding agents. ${ }^{24-26}$ Although ceramic-based composites could achieve high EMI SE by incorporating highly conductive nanofillers, their SSE was generally lower especially than those of conductive polymer-based composites owning to their relatively higher density. Consequently, it is of vital importance to choose suitable ceramic matrix with much lower density. Meanwhile, the chosen ceramic matrix should exhibit satisfactory mechanical properties and thermal stability, especially at high temperatures.

Boron carbide $\left(\mathrm{B}_{4} \mathrm{C}\right)$ is one of the most light-weight ceramics with a density of only $2.52 \mathrm{~g} \mathrm{~cm}^{-3}$ which is comparable to polymer matrix. ${ }^{27}$ In addition, the excellent hardness, mechanical strength and thermal stability render $\mathrm{B}_{4} \mathrm{C}$ ceramics promising candidates of high-temperature structural EMI shielding ceramic matrix. ${ }^{27}$ The semiconducting characteristic of $\mathrm{B}_{4} \mathrm{C}$ could also largely benefit the EMI shielding in comparison to other insulating ceramics. ${ }^{28}$ Accordingly, it can be expected that $\mathrm{B}_{4} \mathrm{C}$ will be one of the most suitable ceramic matrices for high-temperature EMI shielding. Our previous study has demonstrated that the room-temperature EMI SE of $\mathrm{B}_{4} \mathrm{C}$ could be significantly enhanced by adding GNPs. ${ }^{29}$ Nevertheless, the EMI shielding properties of $\mathrm{B}_{4} \mathrm{C}$-based composites at elevated temperatures still needs to be evaluated and the underlying mechanisms for the high shielding properties needs further clarification.

In this study, $\mathrm{B}_{4} \mathrm{C}$ was chosen as the ceramic matrix with 02 vol\% GNPs being uniformly dispersed. The electrical, dielectric and EMI shielding properties of the obtained $\mathrm{GNP} / \mathrm{B}_{4} \mathrm{C}$ composites were systematically investigated in the temperature range from 25 to $800{ }^{\circ} \mathrm{C}$ at the frequency range of $8.2-12.4 \mathrm{GHz}$ (X-band). The origins of the high EMI shielding properties were explored and related mechanisms were presented.

\section{Experimental}

\section{Composites preparation}

GNPs were purchased from Deyang Carbonene Technology Co.,Ltd. The GNPs are stacks of graphene sheets about 6-8 nm in thickness and $5-10 \mu \mathrm{m}$ in level dimensions. GNPs were first dispersed in isopropanol and sonicated for $1 \mathrm{~h} . \mathrm{B}_{4} \mathrm{C}$ powders (Grade HS, H. C. Starck GmbH, Germany) mixed with different amount of GNPs dispersion (0-2 vol\%) and $10 \mathrm{vol} \% \mathrm{Ti}_{3} \mathrm{AlC}_{2}$ powders (purity $>98 \%$, Forsman, China) as sintering aid were homogenized by attrition milling in isopropanol media for $10 \mathrm{~h}$. Afterwards, the slurry was dried and then sieved. The mixed powders were placed in a $50 \mathrm{~mm}$ diameter graphite die and hotpressed in vacuum under $1900{ }^{\circ} \mathrm{C}$ for $30 \mathrm{~min}$. A uniaxial pressure of $30 \mathrm{MPa}$ was applied during sintering. The bulk density of the sintered samples was measured by the Archimedes' method.
The microstructural characterizations of the samples were determined by scanning electron microscopy (SEM, JEOL JSM 6300) and transmission electron microscopy (TEM, JEM-2100). The crystal structure of the samples was studied by X-ray diffraction (XRD). The crystal structure refinement was carried out using the FullProf program based on a triphase system with structural models of $\mathrm{TiB}_{2}, \mathrm{~B}_{4} \mathrm{C}$ and $\mathrm{Al}_{2} \mathrm{O}_{3}$. The diffraction lines were modelled by a pseudo-Voigt function convoluted with axial divergence asymmetry function and the background was modelled by a linear interpolation between a set of fixed points. The following parameters were also refined for each phase: the scale factor, the zero point of detector, the unit-cell parameters, the atomic site coordinates, and the overall displacement parameter.

\section{Evaluation of EMI properties}

The room-temperature electrical conductivity was measured with four-probe (dc power supply Agilent E364 $\times \mathrm{A}$ ) on samples with a dimension of $13.0 \times 2.5 \times 2.5 \mathrm{~mm}^{3}$ using a tubular support of alumina as holder. For EMI SE characterization, specimens with dimensions of $22.86 \times 10.16 \times 1.50 \mathrm{~mm}^{3}$ were cut and polished. The magnitudes of complex scattering parameters ( $S$-parameters) that correspond to reflection $\left(S_{11}\right.$ or $\left.S_{22}\right)$ and transmission $\left(S_{21}\right.$ or $S_{12}$ ) in the X-band frequency were determined through waveguide method with a vector network analyzer (Agilent N5230A). For accuracy of measurement, the device is carefully calibrated with Through-Reflect-Line (TRL) approach. The hightemperature measurement of SE was performed in a waveguide heated by an inner heater at a rate of $10^{\circ} \mathrm{C} \mathrm{min}^{-1}$. The temperature range is $25-800{ }^{\circ} \mathrm{C}$ with a temperature span of $100{ }^{\circ} \mathrm{C}$, and each temperature spot was stabilized for $10 \mathrm{~min}$ in order to ensure the accuracy of measurements.

The total $\mathrm{SE}\left(\mathrm{SE}_{\mathrm{T}}\right)$ can be applied and characterized as follows: ${ }^{30}$

$$
\mathrm{SE}_{\mathrm{T}}=10 \log \left(P_{\mathrm{i}} / P_{\mathrm{t}}\right)=-10 \log \left|S_{12}\right|^{2}
$$

in which $P_{\mathrm{i}}$ and $P_{\mathrm{t}}$ represent the incident power and transmitted power respectively, $\mathrm{SE}$ due to reflection $\left(\mathrm{SE}_{\mathrm{R}}\right)$ and absorption loss $\left(\mathrm{SE}_{\mathrm{A}}\right)$ were calculated from the $S$-parameters as follows, ${ }^{30}$

$$
\begin{gathered}
\mathrm{SE}_{\mathrm{R}}=-10 \log \left(1-\left|S_{11}\right|^{2}\right) \\
\mathrm{SE}_{\mathrm{A}}=-10 \log \left(\left|S_{21}\right|^{2} /\left(1-\left|S_{11}\right|^{2}\right)\right)
\end{gathered}
$$

\section{Results and discussion}

Fig. 1 shows the XRD profiles of the obtained $\mathrm{GNP} / \mathrm{B}_{4} \mathrm{C}$ composites with 0 and 2 vol\% GNPs. Besides the main diffraction peaks corresponding to $\mathrm{B}_{4} \mathrm{C}, \mathrm{TiB}_{2}$ and $\mathrm{Al}_{2} \mathrm{O}_{3}$ phases were also detected in all composites. The presence of $\mathrm{TiB}_{2}$ and $\mathrm{Al}_{2} \mathrm{O}_{3}$ phases can be ascribed to the reactions between $\mathrm{B}_{4} \mathrm{C}$ and $\mathrm{Ti}_{3} \mathrm{AlC}_{2}$ at high temperatures, as suggested in our previous study. ${ }^{31}$ The diffraction peak at $\sim 26^{\circ}$ reveals the presence of carbon, which is related to the residual carbon from reactions 

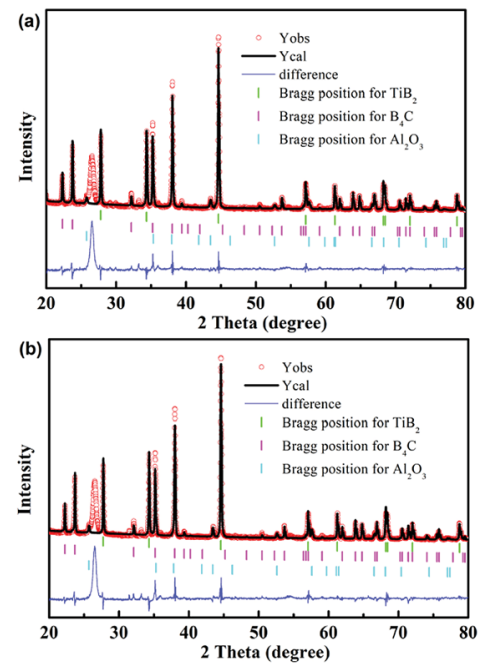

Fig. 1 Typical XRD patterns and XRD refinements of $\mathrm{GNP} / \mathrm{B}_{4} \mathrm{C}$ composites with (a) 0 vol\% and (b) 2 vol\% GNPs.

between $\mathrm{B}_{4} \mathrm{C}$ and $\mathrm{Ti}_{3} \mathrm{AlC}_{2}{ }^{32}$ The XRD refinements were performed in order to obtained the amount of different phases. The amorphous carbon the residual carbon from reactions between $\mathrm{B}_{4} \mathrm{C}$ and $\mathrm{Ti}_{3} \mathrm{AlC}_{2}$ was not considered during the refinement. According to the refinement results, the molar ratios of $\mathrm{TiB}_{2}, \mathrm{~B}_{4} \mathrm{C}$ and $\mathrm{Al}_{2} \mathrm{O}_{3}$ phases are around $13 \%, 83 \%$ and $4 \%$ respectively. Table 1 summarizes the phase composition, density and electrical conductivity of various $\mathrm{GNP} / \mathrm{B}_{4} \mathrm{C}$ composites. All composites exhibit similar density which is slightly higher than that of monolithic $\mathrm{B}_{4} \mathrm{C}$ ceramics due to the presence of $\mathrm{TiB}_{2}$. The existence of highly conductive $\mathrm{TiB}_{2}$ phase also enhances the electrical conductivity of the composites. The composites without GNPs exhibit a moderate electrical conductivity of $27 \mathrm{~S} \mathrm{~m}^{-1}$, which is higher than that of monolithic $\mathrm{B}_{4} \mathrm{C}$ ceramics. ${ }^{28}$ With the increase of GNPs loading, the electrical conductivity increases monotonically. A jump of electrical conductivity occurs at $1 \mathrm{vol} \%$ GNPs loading and a maximum value of $1850 \mathrm{~S} \mathrm{~m}^{-1}$ was obtained in composites with 2 vol\% GNPs. The enhancement of electrical conductivity is generally ascribed to the formation of numerous conducting paths by GNPs layers and $\mathrm{TiB}_{2}$ particles. ${ }^{32}$

Fig. 2 displays the fracture surfaces of the $G N P / B_{4} C$ composites with different GNP loadings. All the $\mathrm{B}_{4} \mathrm{C}$ composites show dense microstructures, demonstrating the effective promotion of densification of $\mathrm{B}_{4} \mathrm{C}$ by adding $\mathrm{Ti}_{3} \mathrm{AlC}_{2}$. The $\mathrm{B}_{4} \mathrm{C}$ exhibits a uniform size distribution with a fine grain size around $0.5 \mu \mathrm{m}$. The presence of $\mathrm{TiB}_{2}$ particles can be observed in all composites, as indicated in the red circles in Fig. 2(a). The

Table 1 Density and electrical conductivity of $\mathrm{GNP} / \mathrm{B}_{4} \mathrm{C}$ composites

\begin{tabular}{llc}
\hline $\begin{array}{l}\text { GNPs content } \\
(\text { vol\%) }\end{array}$ & $\begin{array}{l}\text { Density } \\
\left(\mathrm{g} \mathrm{cm}^{-3}\right)\end{array}$ & $\begin{array}{l}\text { Electrical conductivity } \\
\left(\mathrm{S} \mathrm{m}^{-1}\right)\end{array}$ \\
\hline 0.0 & 2.63 & $27 \pm 5$ \\
0.5 & 2.60 & $35 \pm 4$ \\
1.0 & 2.58 & $980 \pm 12$ \\
2.0 & 2.57 & $1850 \pm 17$
\end{tabular}

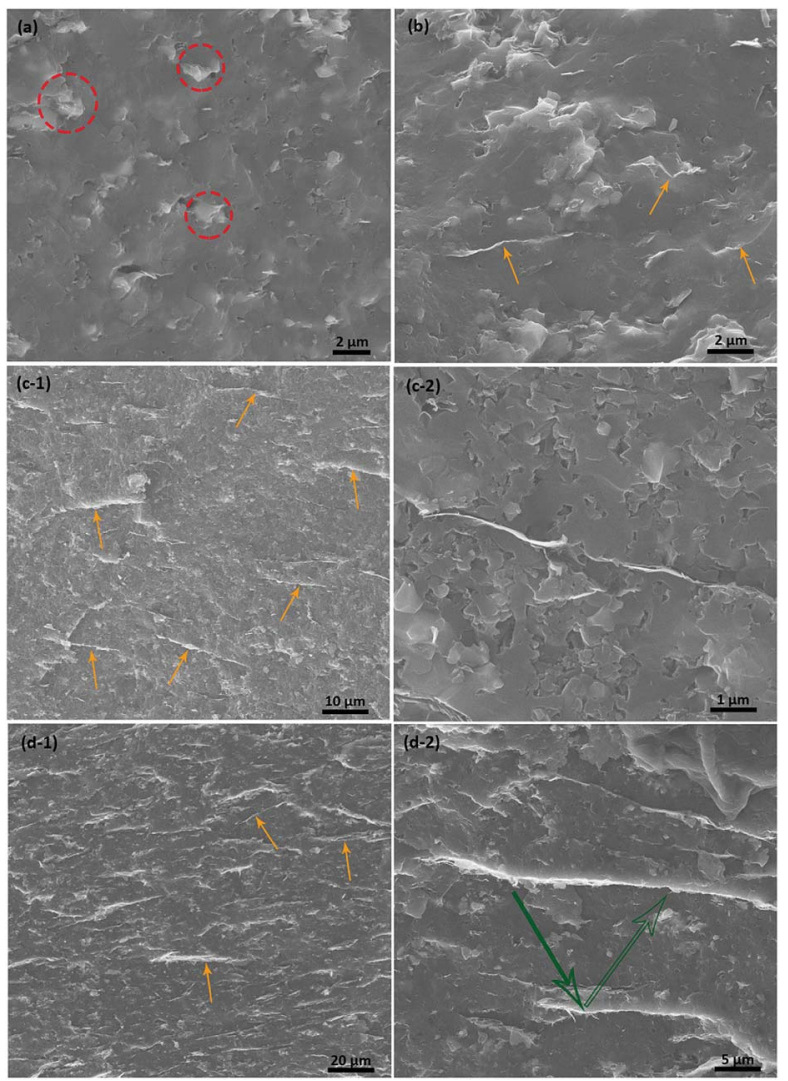

Fig. 2 Fracture surfaces of $\mathrm{GNP} / \mathrm{B}_{4} \mathrm{C}$ composites with different $\mathrm{GNP}$ loading. (a) 0 vol\%; (b) 0.5 vol\%; (c-1) and (c-2) 1 vol\%; (d-1) and (d-2) 2 vol\%.

GNPs could be easily distinguished as the thin layers indicated by yellow arrows in Fig. 2(c-1) and (d-1). It can be seen that the GNPs were distributed uniformly in all $\mathrm{GNP} / \mathrm{B}_{4} \mathrm{C}$ composites. The GNPs are more uniformly distributed compared to our previous study due to the utilization of isopropanol as dispersion media. ${ }^{32}$ Correspondingly, the electrical conductivity becomes slightly higher as demonstrated in Table 1 . The level dimension of GNPs layers varies from several micrometres to tens of micrometres, which is consistent with the raw GNPs layers. GNP layers with a level dimension over $20 \mu \mathrm{m}$ were occasionally seen as indicated in Fig. 2(d-2). The level dimension of GNPs in this study is apparently larger than most studies in literature. ${ }^{1-3}$ Accordingly, the GNP layers show certain degree of parallel alignment under high applied pressure during sintering, as demonstrated in Fig. 2(c-1) and (d-1). The large level dimensions and texture-like alignment of GNPs are highly desirable and were supposed to induce high EMI shielding efficiency for electromagnetic waves that emanate through the thickness direction. ${ }^{20,33}$ Fig. 3(a) and (b) display the TEM images of the $\mathrm{GNP} / \mathrm{B}_{4} \mathrm{C}$ composites at lower and higher resolutions respectively. GNP was found to locate well along the grain boundaries. A simple estimate taking into account the thickness of the single graphene sheets $(\sim 2 \mathrm{~nm})$ gives a proportion of $\sim 30$ layers of graphene in the observed GNP sheet. The relatively higher observed thickness is a consequence of two GNPs stacking closely together, as shown in Fig. 3(b). 


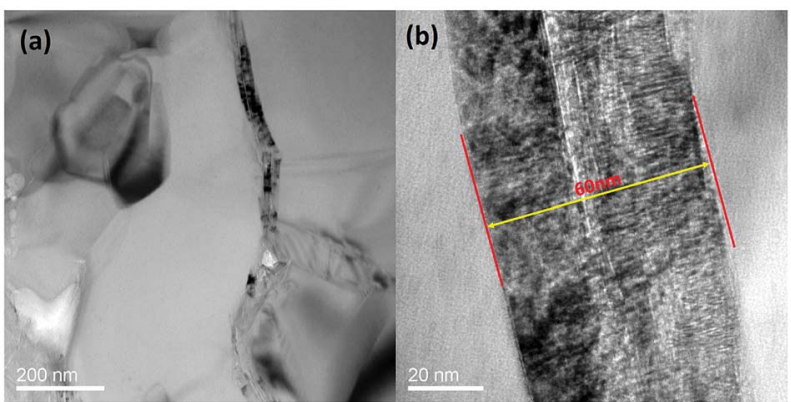

Fig. 3 TEM images of $\mathrm{B}_{4} \mathrm{C} / \mathrm{GNP}$ composites with 2 vol\% GNPs. (a) Lower magnification; (b) higher magnification.

Fig. 4(a) compares the total room-temperature EMI SE $\left(\mathrm{SE}_{\mathrm{T}}\right)$ of GNP/ $/ \mathrm{B}_{4} \mathrm{C}$ composites with different GNPs content measured at the $\mathrm{X}$-band frequency range. The $\mathrm{SE}_{\mathrm{T}}$ of $\mathrm{B}_{4} \mathrm{C}$ composite without GNPs shows a relatively high value $(\sim 32 \mathrm{~dB})$ with a tiny variation at the measured frequency range. The high $\mathrm{SE}_{\mathrm{T}}$ could be mainly attributed to the semiconducting nature of $\mathrm{B}_{4} \mathrm{C}$ matrix and the presence of highly conductive $\mathrm{TiB}_{2}$ particles. The addition of $0.5 \mathrm{vol} \%$ GNPs gives rise to a slight enhancement of the $\mathrm{SE}_{\mathrm{T}}$ to $\sim 33 \mathrm{~dB}$. With further increase of GNPs, $\mathrm{SE}_{\mathrm{T}}$ increased remarkably and a maximum $\mathrm{SE}_{\mathrm{T}}$ close to $40 \mathrm{~dB}$ was obtained in $\mathrm{GNP} / \mathrm{B}_{4} \mathrm{C}$ composite with only 2 vol\% GNPs which is almost the lowest amount of nano-fillers required to achieve such a high $\mathrm{EMI}_{\mathrm{SE}}$ in reported ceramic- or even polymer-based composites. ${ }^{1-3,7,20}$ Correspondingly, $99.99 \%$ of the incident EMI energy could be effectively shielded at room-temperature for $\mathrm{GNP} / \mathrm{B}_{4} \mathrm{C}$ composite with 2 vol\% GNPs. The overall EMI $\mathrm{SE}_{\mathrm{T}}$ could be
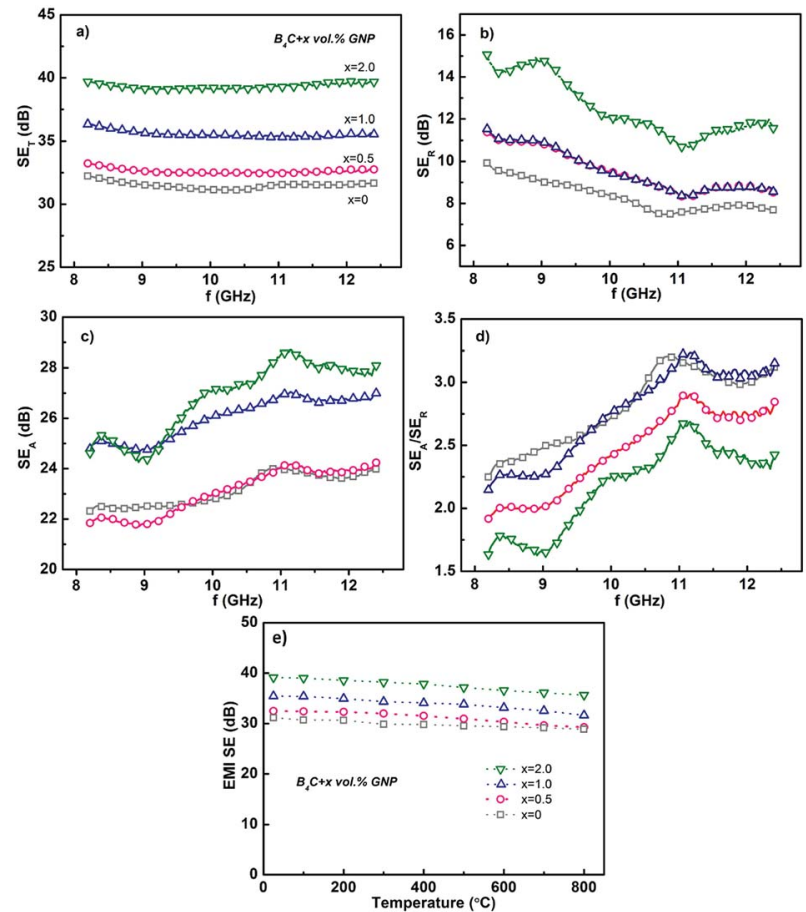

Fig. 4 (a)-(c) represent the frequency dependencies of $S E_{T}, S E_{R}$ and $\mathrm{SE}_{\mathrm{A}}$ respectively of $\mathrm{GNP} / \mathrm{B}_{4} \mathrm{C}$ composites at room temperature; (d) frequency dependency of $\mathrm{SE}_{\mathrm{A}} / \mathrm{SE}_{\mathrm{R}}$; (e) temperature dependency of $\mathrm{SE}_{\mathrm{T}}$ for $\mathrm{GNP} / \mathrm{B}_{4} \mathrm{C}$ composites with different GNP loading. further divided into three parts which correspond to reflection $\left(\mathrm{SE}_{\mathrm{R}}\right)$, absorption $\left(\mathrm{SE}_{\mathrm{A}}\right)$ and the multiple reflections $\left(\mathrm{SE}_{\mathrm{M}}\right)$ respectively. ${ }^{34}$ The multiple reflection effect, nevertheless, is included in the absorption because the re-reflected waves could get absorbed or dissipated within the composite material. ${ }^{23}$ Accordingly, the $\mathrm{SE}_{\mathrm{T}}$ of $\mathrm{GNP} / \mathrm{B}_{4} \mathrm{C}$ composites could be expressed as follows for simplicity,

$$
\mathrm{SE}_{\mathrm{T}}=\mathrm{SE}_{\mathrm{R}}+\mathrm{SE}_{\mathrm{A}}
$$

The frequency dependences of the $\mathrm{SE}_{\mathrm{R}}$ and $\mathrm{SE}_{\mathrm{A}}$ of $\mathrm{GNP} / \mathrm{B}_{4} \mathrm{C}$ composites were exhibited in Fig. 4(b) and (c) respectively. The $\mathrm{SE}_{\mathrm{R}}$ exhibits a significant enhancement when the GNPs loading is higher than $1 \mathrm{vol} \%$, which is in consistency with the dependence of electrical conductivity on GNPs loading. The composite with 2 vol\% GNPs shows high $\mathrm{SE}_{\mathrm{R}}$ in the range of 11$15 \mathrm{~dB}$. The high $\mathrm{SE}_{\mathrm{R}}$ can be ascribed to the giant impedance mismatch between $\mathrm{GNP} / \mathrm{B}_{4} \mathrm{C}$ composites and the free air. In theory, for a plane wave radiation, the far field reflection loss $\left(\mathrm{SE}_{\mathrm{R}}\right)$ is given by

$$
\mathrm{SE}_{\mathrm{R}}=39.5+10 \log \sigma /(2 \pi f \mu)
$$

where $\sigma$ is the electrical conductivity, $f$ is the frequency and $\mu$ is the permeability. The $\mathrm{SE}_{\mathrm{R}}$ tends to decrease with increasing frequency according to the above equation which is well consistent with the results shown in Fig. 4(b). If we substitute the electrical conductivity (shown in Table 1), frequency (8.2$12.4 \mathrm{GHz}$ ) and permeability (assumed to be 1 for all composites) into eqn (5), the $\mathrm{SE}_{\mathrm{R}}$ was calculated to be around $20 \mathrm{~dB}$ for composite with 2 vol\% GNPs. The relatively lower experimentally obtained values could be ascribed to the secondary reflections of reflected radiation due to the presence of GNP layers. Compared to $\mathrm{SE}_{\mathrm{R}}$, all $\mathrm{GNP} / \mathrm{B}_{4} \mathrm{C}$ composites exhibit considerably higher absorption loss $\mathrm{SE}_{\mathrm{A}}$. The composites with 0 and 0.5 vol\% GNPs exhibit similar $\mathrm{SE}_{\mathrm{A}}$ between 22 and $24 \mathrm{~dB}$. The $\mathrm{SE}_{\mathrm{A}}$ shows a step increase at $1 \mathrm{vol} \%$ GNPs loading and no further significant improvement was observed with further increasing GNP loading to 2 vol\%. High $\mathrm{SE}_{\mathrm{A}}$ values between 25 and $28 \mathrm{~dB}$ were obtained in composite with 2 vol\% GNPs. The $\mathrm{SE}_{\mathrm{A}}$ of all composites tend to increase with increasing frequency, which is attributed to the increased effective thickness of the composites with decreasing wavelength. The ratios between $\mathrm{SE}_{\mathrm{A}}$ and $\mathrm{SE}_{\mathrm{R}}$ were calculated and shown in Fig. 4(d). The $\mathrm{SE}_{\mathrm{A}} / \mathrm{SE}_{\mathrm{R}}$ ratios exhibit high values between 1.5 and 3.5 indicating that the $\mathrm{SE}_{\mathrm{A}}$ made a dominant contribution to the $\mathrm{SE}_{\mathrm{T}}$ for all composites. The high-temperature EMI shielding of $\mathrm{GNP} / \mathrm{B}_{4} \mathrm{C}$ composites was evaluated up to $800{ }^{\circ} \mathrm{C}$ and the temperature dependences of $\mathrm{SE}_{\mathrm{T}}$ for different $\mathrm{GNP} / \mathrm{B}_{4} \mathrm{C}$ composites at $10 \mathrm{GHz}$ were shown in Fig. 4(e). The EMI $\mathrm{SE}_{\mathrm{T}}$ of all $\mathrm{GNP} / \mathrm{B}_{4} \mathrm{C}$ composites exhibit satisfactory thermal stability and they experienced only a slight decrease with increasing temperature. This is consistent with the results of graphene oxides (GO) composites for which the $\mathrm{SE}_{\mathrm{T}}$ decreases with increasing temperature when the GO mass is below $8 \mathrm{vol} \%{ }^{3}$ The slight decrease of $\mathrm{SE}_{\mathrm{T}}$ with increasing temperature can be 
Table 2 Electromagnetic shielding performance of representative ceramic-based composites

\begin{tabular}{|c|c|c|c|c|c|c|c|}
\hline \multirow[b]{2}{*}{ Matrix } & \multirow[b]{2}{*}{ Filler and loading } & \multirow[b]{2}{*}{ Thickness (mm) } & \multirow[b]{2}{*}{ Frequency range } & \multirow[b]{2}{*}{ Temperature range } & \multicolumn{2}{|c|}{ EMI SE (dB) } & \multirow[b]{2}{*}{ Ref. } \\
\hline & & & & & $\mathrm{RT}$ & HT & \\
\hline $\mathrm{SiO}_{2}$ & MWCNT 10 wt\% & 2.5 & $\mathrm{X}$ band & $100-500{ }^{\circ} \mathrm{C}$ & $\sim 21$ & $\sim 23$ & 17 \\
\hline $\mathrm{SiO}_{2}$ & $\mathrm{C}_{\mathrm{f}} 20 \mathrm{wt} \%$ & 2.5 & $\mathrm{X}$ band & $25-600{ }^{\circ} \mathrm{C}$ & $\sim 12$ & $\sim 12$ & 15 \\
\hline $\mathrm{SiO}_{2}$ & $\mathrm{OMC}^{a} 10$ vol $\%$ & 5.0 & $\mathrm{X}$ band & $25^{\circ} \mathrm{C}$ & $\sim 40$ & - & 37 \\
\hline $\mathrm{SiC}_{\mathrm{f}} / \mathrm{SiC}$ & $\mathrm{PyC}^{b} 3.3$ vol\% & 2.0 & $\mathrm{X}$ band & $25^{\circ} \mathrm{C}$ & $\sim 26$ & & 35 \\
\hline $\mathrm{Al}_{2} \mathrm{O}_{3}$ & GNP 2 vol\% & 1.5 & $\mathrm{X}$ band & $25-400{ }^{\circ} \mathrm{C}$ & $\sim 23$ & $\sim 37$ & 2 \\
\hline $\mathrm{Al}_{2} \mathrm{O}_{3}$ & $\mathrm{Ti}_{3} \mathrm{SiC}_{2} 25$ vol $\%$ & 1.0 & Ku-band & $25^{\circ} \mathrm{C}$ & $\sim 32$ & - & 13 \\
\hline $\mathrm{BaTiO}_{3}$ & GNP $4 \mathrm{wt} \%$ & 1.5 & $\mathrm{X}$ band & $25^{\circ} \mathrm{C}$ & $\sim 42$ & - & 1 \\
\hline $\mathrm{Ti}_{3} \mathrm{AlC}_{2}$ & - & 1.5 & $\mathrm{X}$ band & $25-800{ }^{\circ} \mathrm{C}$ & $\sim 34$ & $\sim 31$ & 7 \\
\hline 3Y-TZP & MWCNT 9 wt\% & 1.0 & Ku band & $25^{\circ} \mathrm{C}$ & $25-30$ & - & 8 \\
\hline
\end{tabular}

ascribed to the higher defect mobility and therefore the decreased dielectric loss at high temperatures. Although with a slight decrease, the $\mathrm{GNP} / \mathrm{B}_{4} \mathrm{C}$ composites still show high EMI $\mathrm{SE}_{\mathrm{T}}$ even at temperature as high as $800{ }^{\circ} \mathrm{C}$. Especially, the GNP/ $\mathrm{B}_{4} \mathrm{C}$ composites with 2 vol\% GNPs exhibit high $\mathrm{SE}_{\mathrm{T}}$ larger than $35 \mathrm{~dB}$ at $800{ }^{\circ} \mathrm{C}$, demonstrating that $\mathrm{GNP} / \mathrm{B}_{4} \mathrm{C}$ composites are efficient high-temperature EMI shielding materials.

Table 2 compares the EMI SE of various advanced ceramic composites reported in literatures. ${ }^{1-3,8,13-17,22,35-37}$ It can be observed that considerably high EMI SE over $30 \mathrm{~dB}$ can be achieved in many ceramic composites by incorporating highly conductive nanofillers such as $\mathrm{C}_{\mathrm{f}}$, CNT, GNP and $\mathrm{Ti}_{3} \mathrm{AlC}_{2}$ particles. More importantly, their high EMI SE could be well maintained or even enhanced at high temperatures up to $600{ }^{\circ} \mathrm{C}$. However, the high EMI SE of most ceramic composites was achieved either by high filler loading or large thickness. Moreover, the preparation of some ceramics such as $\mathrm{SiC} / \mathrm{SiC}$ composites with high $\mathrm{SE}$ is costly and time-consuming compared to the preparation of $\mathrm{GNP} / \mathrm{B}_{4} \mathrm{C}$ composite in this study. It seems that only $\mathrm{Al}_{2} \mathrm{O}_{3}$ composites with 2 vol\% GNPs exhibit similar EMI shielding properties with $\mathrm{B}_{4} \mathrm{C}$ composites in this study. However, the density of $\mathrm{Al}_{2} \mathrm{O}_{3}$ is much higher than $\mathrm{B}_{4} \mathrm{C}$. Regarding the aerospace applications of EMI shielding materials, the specific EMI shielding effectiveness SSE (SE divided by density of composite) is more appropriate to judge the shielding performances of different shielding composites. ${ }^{23,24}$ Nevertheless, SSE alone is not a sufficient parameter for understanding overall effectiveness, as a higher SSE can simply be achieved at a larger thickness, which directly increases the weight of the final product. Therefore, a more realistic parameter is to divide SSE by the material thickness (SSE/t). Fig. 5 shows the temperature dependent SSE/ $t$ of various EMI shielding composites reported in literature and this study. It can be observed that metals exhibit both lower SSE/ $t$ values and lower application temperature; carbon/polymer composites show extremely high SSE/t values while lower application temperature (generally lower than $300{ }^{\circ} \mathrm{C}$ ); Traditional ceramic-based composites exhibit the highest application temperature $(\geq 400$ ${ }^{\circ} \mathrm{C}$ ) while relatively lower SSE/ $t$ values which are comparable to metals such as copper. GNP/ $\mathrm{B}_{4} \mathrm{C}$ composite with 2 vol\% GNPs in this study exhibits simultaneously high $\operatorname{SSE} / t$ values and application temperature. The high SSE $/ t$ around $100 \mathrm{~dB} \mathrm{~cm}{ }^{2} \mathrm{~g}^{-1}$ were well maintained up to $800{ }^{\circ} \mathrm{C}$. It can be concluded that $\mathrm{GNP} / \mathrm{B}_{4} \mathrm{C}$ composite with $2 \mathrm{vol} \%$ GNPs in this study exhibit the highest EMI shielding efficiency both at temperatures higher than $400^{\circ} \mathrm{C}$ in all EMI shielding composites investigated so far, indicating that the application of $\mathrm{B}_{4} \mathrm{C} / \mathrm{GNP}$ composites as lightweight structural EMI shielding materials at high temperatures is highly promising.

Generally, the high shielding properties of $\mathrm{GNP} / \mathrm{B}_{4} \mathrm{C}$ composites can be attributed to the high reflection loss and absorption loss. The high reflection loss comes from the highly conductive networks formed by GNPs and $\mathrm{TiB}_{2}$. The absorption of the radiation could arise from different energy dissipation processes as ohmic loss, dielectric loss and magnetic loss. ${ }^{35}$ In $\mathrm{GNP} / \mathrm{B}_{4} \mathrm{C}$ composites magnetic loss can be generally neglected.

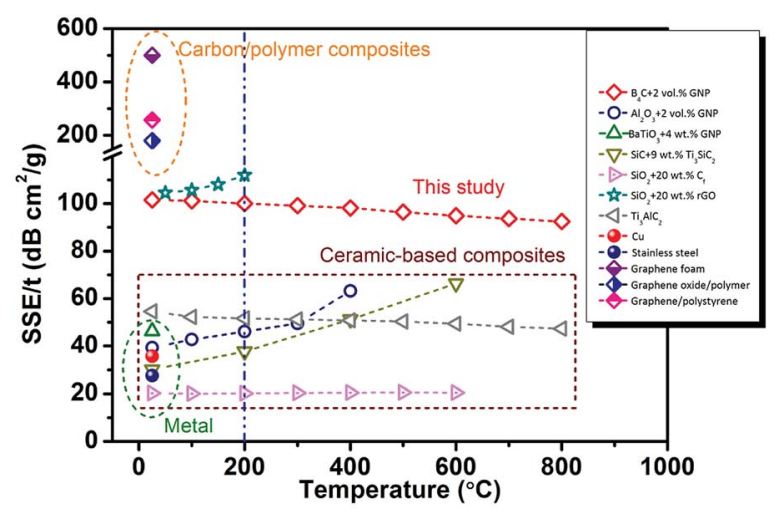

Fig. 5 Comparison of SSE/t for typical EMI shielding materials reported in literature and this study. 
The ohmic loss is mainly due to the high electrical conductivity of $\mathrm{GNP} / \mathrm{B}_{4} \mathrm{C}$ composites. Compared to ohmic loss, the dielectric loss is expected to make a dominant contribution to the high attenuation of microwave in $\mathrm{GNP} / \mathrm{B}_{4} \mathrm{C}$ composites. Fig. 6(a) illustrates the real part of the complex permittivity of $\mathrm{GNP} / \mathrm{B}_{4} \mathrm{C}$ composites with different GNP loadings. Composite without GNPs exhibit relatively high permittivity between 200 and 400 in the X-band frequency range and it decreases gradually with increasing frequency, which is higher than the reported values in literatures. The high permittivity of $\mathrm{B}_{4} \mathrm{C}$ composites mainly arises from the hopping electrons of $\mathrm{B}_{4} \mathrm{C}$ and free electrons in $\mathrm{TiB}_{2}$ phase. Besides, the defects produced during hightemperature sintering and reactions could also contribute to the high permittivity. With the increase of GNPs content, the real permittivity keeps decreasing to $\sim 50$ at 1 vol\% GNPs. With further increasing GNPs content, no more decrease of permittivity was observed. The significantly decreased real permittivity can be ascribed to the weaken ability to storage electrical charges by the formation of highly conductive GNPs networks in $\mathrm{B}_{4} \mathrm{C}$ composites with high GNPs loading. Being opposite to the real part of permittivity, the dielectric loss $\tan \delta$ defined as the ratio between the imaginary and the real part of the complex permittivity of $\mathrm{GNP} / \mathrm{B}_{4} \mathrm{C}$ composites increases monotonically with increasing GNP content, as exhibited in Fig. 6(b). When the GNP content is below $1 \mathrm{vol} \%$, the dielectric loss kept around 1 . GNP/ $\mathrm{B}_{4} \mathrm{C}$ composite with $2 \mathrm{vol} \%$ GNPs exhibit a highly lossy characteristic with extremely high dielectric loss between 1 and 9. The high dielectric loss of $\mathrm{GNP} / \mathrm{B}_{4} \mathrm{C}$ composites can be ascribed to the high imaginary permittivity which was generally described as below, ${ }^{7}$

$$
\varepsilon^{\prime \prime}=\varepsilon_{\text {Relax }}^{\prime \prime}+\sigma / \omega \varepsilon_{0}
$$

where $\varepsilon_{\text {Relax }}^{\prime \prime}$ is the electron relaxation polarization, $\sigma$ is the electrical conductivity, $\varepsilon_{0}$ is the dielectric constant in vacuum, and $\omega$ is the angular frequency. The first term in eqn (6) is related to the relaxation loss of microwave and arises mainly from interface polarization and defects produced during hightemperature sintering. The last term corresponds to the conductance loss resulted from the formation of conductive nanofiller networks acting as dissipating mobile charge carriers in the composites. The high conductivity gives rise to high imaginary permittivity and consequently high electromagnetic radiation dissipation. Besides the high dielectric loss, the high absorption loss of $\mathrm{GNP} / \mathrm{B}_{4} \mathrm{C}$ composites partially arises from the presence of aligned two-dimensional nano-layered
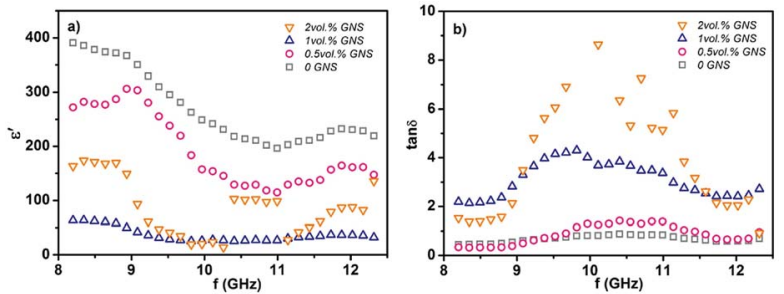

Fig. 6 (a) The real permittivity and (b) the dielectric loss of various $\mathrm{GNP} / \mathrm{B}_{4} \mathrm{C}$ composites. architecture. $^{20,33}$ The parallel aligned GNPs layers could induce multiple reflections inside the composites. The multiple reflections prolong the EM wave propagation path and enhance the absorption accordingly. The multiple reflections are speculated to be responsible for the different EMI shielding efficiency in composites containing GNP and CNT. With increasing temperature, the dielectric loss decreased due to the lower internal friction during the rotation of the dipoles, thereby leads to a slight decrease of $\mathrm{SE}_{\mathrm{T}}$.

\section{Conclusions}

Light-weight $\mathrm{B}_{4} \mathrm{C}$ composites with high EMI shielding properties were successfully obtained by incorporating a small amount of GNPs. The composites containing only 2 vol\% GNPs exhibit a high room-temperature shielding effectiveness around $40 \mathrm{~dB}$ and a satisfactory shielding effectiveness over $35 \mathrm{~dB}$ at $800^{\circ} \mathrm{C}$ in the whole X-band frequency range. A high SSE $/ t$ around $100 \mathrm{~dB}$ $\mathrm{cm}^{2} \mathrm{~g}^{-1}$ which was almost the highest value reported in ceramic-based shielding composites was achieved in $\mathrm{GNP} / \mathrm{B}_{4} \mathrm{C}$ composites containing 2 vol\% GNPs. The outstanding shielding performance of $\mathrm{GNP} / \mathrm{B}_{4} \mathrm{C}$ composites was ascribed to: (1) high reflection loss and ohmic loss due to high electrical conductivity; (2) high dielectric loss resulting from the interfacial polarization and large amounts of defects; (3) multiple reflections by parallel-aligned GNP layers.

\section{Conflicts of interest}

There are no conflicts to declare.

\section{Acknowledgements}

This work was supported by the National Natural Science Foundation of China (Grants No. 91326102 and 51532009), and the Science and Technology Development Foundation of China Academy of Engineering Physics (Grant No. 2013A0301012). Haibin Zhang is grateful to the foundation by the Recruitment Program of Global Youth Experts and the Youth Hundred Talents Project of Sichuan Province.

\section{Notes and references}

1 Y. Qing, Q. Wen, F. Luo, W. Zhou and D. Zhu, J. Mater. Chem. C, 2016, 4, 371-375.

2 Y. Qing, Q. Wen, F. Luo and W. Zhou, J. Mater. Chem. C, 2016, 4, 4853-4862.

3 B. Wen, M. Cao, M. Lu, W. Cao, H. Shi, J. Liu, X. Wang, H. Jin, X. Fang, W. Wang and J. Yuan, Adv. Mater., 2014, 26, 34843489.

4 X. Yin, L. Kong, L. Zhang, L. Cheng, N. Travitzky and P. Greil, Int. Mater. Rev., 2014, 59, 326-355.

5 B. Zhang, J. Li, J. Sun, S. Zhang, H. Zhai and Z. Du, J. Eur. Ceram. Soc., 2002, 22, 93-99.

6 X. Li, L. Zhang, X. Yin, L. Feng and Q. Li, Scr. Mater., 2010, 63, 657-660. 
7 Y. Mu, W. Zhou, F. Wan, D. Ding, Y. Hu and F. Luo, Composites, Part A, 2015, 77, 195-203.

8 S. Shi and L. Ji, Nanotechnology, 2008, 19, 255707.

9 J.-M. Thomassin, C. Jérôme, T. Pardoen, C. Bailly, I. Huynen and C. Detrembleur, Mater. Sci. Eng., R, 2013, 74, 211-232.

10 Y. Yang, M. C. Gupta, K. L. Dudley and R. W. Lawrence, Nano Lett., 2005, 5, 2131-2134.

11 D. Yan, H. Pang, B. Li, R. Vajtai, L. Xu, P. Ren, J. Wang and Z. Li, Adv. Funct. Mater., 2015, 25, 559-566.

12 M. H. Al-Saleh, W. H. Saadeh and U. Sundararaj, Carbon, 2013, 60, 146-156.

13 S. Shi, L. Zhang and J. Li, J. Appl. Phys., 2008, 103, 124103.

14 L. Chen, X. Yin, X. Fan, M. Chen, X. Ma, L. Cheng and L. Zhang, Carbon, 2015, 95, 10-19.

15 M. Cao, W. Song, Z. Hou, B. Wen and J. Yuan, Carbon, 2010, 48, 788-796.

16 Y. Qing, Y. Mu, Y. Zhou, F. Luo, D. Zhu and W. Zhou, Eur. Ceram. Soc., J., 2014, 34, 2229-2237.

17 B. Wen, M. Cao, Z. Hou, W. Song, L. Zhang, M. Lu, H. Jin, X. Fang, W. Wang and J. Yuan, Carbon, 2013, 65, 124-139.

18 S. H. Xie, Y. Y. Liu and J. Y. Li, Appl. Phys. Lett., 2008, 92, 243121.

19 B. Yuan, L. Yu, L. Sheng, K. An and X. Zhao, J. Phys. D: Appl. Phys., 2012, 45, 235108.

20 N. Yousefi, X. Sun, X. Lin, X. Shen, J. Jia, B. Zhang, B. Tang, M. Chan and J.-K. Kim, Adv. Mater., 2014, 26, 5480-5487.

21 J. Wang and Y. Zhou, Annu. Rev. Mater. Res., 2009, 39, 415443.

22 Y. Tan, H. Luo, H. Zhang, X. Zhou and S. Peng, Scr. Mater., 2017, 134, 47-51.
23 F. Shahzad, M. Alhabeb, C. B. Hatter, B. Anasori, S. Man Hong, C. M. Koo and Y. Gogotsi, Science, 2016, 353, 11371140.

24 Z. Chen, C. Xu, C. Ma, W. Ren and H. Cheng, Adv. Mater., 2013, 25, 1296-1300.

25 B. Shen, Y. Li, D. Yi, W. Zhai, X. Wei and W. Zheng, Carbon, 2016, 102, 154-160.

26 Y. Zhang, Y. Huang, T. Zhang, H. Chang, P. Xiao, H. Chen, Z. Huang and Y. Chen, Adv. Mater., 2015, 27, 2049-2053.

27 F. Thévenot, J. Eur. Ceram. Soc., 1990, 6, 205-225.

28 T. L. Aselage, D. Emin and S. S. McCready, Phys. Rev. B, 2001, 64, 054302.

29 Y. Tan, H. Luo, H. Zhang, X. Zhou and S. Peng, AIP Adv., 2016, 6, 035208.

30 M. H. Al-Saleh and U. Sundararaj, Carbon, 2009, 47, 17381746.

31 Y. Tan, H. Luo, H. Zhang, X. Zhou and S. Peng, Ceram. Int., 2016, 42, 7347-7352.

32 Y. Tan, H. Luo, H. Zhang and S. Peng, J. Eur. Ceram. Soc., 2016, 36, 2679-2687.

33 B. Shen, W. Zhai and W. Zheng, Adv. Funct. Mater., 2014, 24, 4542-4548.

34 D. D. L. Chung, Carbon, 2001, 39, 279-285.

35 D. Ding, Y. Shi, Z. Wu, W. Zhou, F. Luo and J. Chen, Carbon, 2013, 60, 552-555.

36 X. Li, L. Zhang and X. Yin, J. Eur. Ceram. Soc., 2013, 33, 647651.

37 J. Wang, C. Xiang, Q. Liu, Y. Pan and J. Guo, Adv. Funct. Mater., 2008, 18, 2995-3002. 